\title{
Mechanical Characterization of Graphene Nanoplatelets- Reinforced Mg-3Sn Alloy Synthesized by Powder Metallurgy
}

\author{
Pravir Kumar $^{1}$, Katerina Skotnicova ${ }^{2}{ }^{(}$, Ashis Mallick ${ }^{1}$, Manoj Gupta ${ }^{3, *(1)}$, Tomas Cegan ${ }^{2}$ and Jan Jurica ${ }^{2}$ \\ 1 Department of Mechanical Engineering, Indian Institute of Technology (ISM) Dhanbad, \\ Dhanbad 826 004, India; pravirkumar30@gmail.com (P.K.); mallick@iitism.ac.in (A.M.) \\ 2 Faculty of Materials Science and Technology, VSB-Technical University of Ostrava, \\ 70800 Ostrava, Czech Republic; katerina.skotnicova@vsb.cz (K.S.); tomas.cegan@vsb.cz (T.C.); \\ jan.jurica@vsb.cz (J.J.) \\ 3 Department of Mechanical Engineering, National University of Singapore, Singapore 117576, Singapore \\ * Correspondence: mpegm@nus.edu.sg; Tel.: +65-6516-6358
}

Citation: Kumar, P.; Skotnicova, K.; Mallick, A.; Gupta, M.; Cegan, T.; Jurica, J. Mechanical Characterization of Graphene NanoplateletsReinforced Mg-3Sn Alloy Synthesized by Powder Metallurgy. Metals 2021, 11, 62. https://doi.org/10.3390/ met11010062

Received: 9 November 2020 Accepted: 25 December 2020 Published: 30 December 2020

Publisher's Note: MDPI stays neutral with regard to jurisdictional clai$\mathrm{ms}$ in published maps and institutional affiliations.

Copyright: $\odot 2020$ by the authors. Licensee MDPI, Basel, Switzerland. This article is an open access article distributed under the terms and conditions of the Creative Commons Attribution (CC BY) license (https:// creativecommons.org/licenses/by/ $4.0 /)$.

\begin{abstract}
The present study investigated the effects of alloying and nano-reinforcement on the mechanical properties (microhardness, tensile strength, and compressive strength) of Mg-based alloys and composites. Pure Mg, Mg-3Sn alloy, and Mg-3Sn + 0.2 GNP alloy-nanocomposite were synthesized by powder metallurgy followed by hot extrusion. The microstructural characteristics of the bulk extruded samples were explored using $\mathrm{X}$-ray diffraction, field-emission scanning electron microscopy, and optical microscopy and their mechanical properties were compared. The microhardness, tensile strength, and compressive strength of the Mg-3Sn alloy improved when compared to those of monolithic $\mathrm{Mg}$ sample and further improvements were displayed by Mg-3Sn + $0.2 \mathrm{GNP}$ alloy-nanocomposite. No significant change in the compressive strain to failure was observed in both the alloy and the alloy-nanocomposite with respect to that of the pure Mg sample. However, an enhanced tensile strain to failure was displayed by both the alloy and the alloy-nanocomposite.
\end{abstract}

Keywords: alloy; nanocomposite; magnesium; synthesis; microstructure; mechanical properties

\section{Introduction}

Magnesium is widely used as a high-performance structural material due to its low density, good hardness, and high specific strength [1-3]. The density ratios of magnesium alloys to aluminum and steel are approximately $2: 3$ and 1:4, respectively, which are comparable to those of plastic and carbon fiber composites. Magnesium also offers other potential properties, such as excellent castability, machinability, weldability, damping, and resistance to electromagnetic radiation $[4,5]$. The melting temperature and specific strength of $\mathrm{Mg}$ are comparable to those of aluminum alloys [6]. $\mathrm{Mg}$ is the lightest structural metal and available in abundance in the earth's crust and seawater. Mg-based alloys and composites are considered as a replacement for heavier materials in manufacturing industries such as steels, titanium, and aluminum alloys. The magnesium alloys find multiple applications in the aircraft, automobile, computers, consumer electronics, and communication sectors. The need for reducing the weight of automobile components after the introduction of the new legislation to low emission has triggered a renewed interest in $\mathrm{Mg}$ alloys [7]. $\mathrm{Mg}$ is also recognized as a potential candidate for medical implants due to its biocompatibility [8,9]. The main commercial alloy systems used are Mg-Al-Zn, Mg-Al, Mg-Zn-Rare earth (RE), and Mg-RE. Approximately $90 \%$ of available commercial alloys are cast alloys and approximately $90 \%$ of the magnesium alloys are processed using high-pressure die casting process. The alloys widely used at room temperature and display excellent strength, ductility, castability, machinability, and fairly good corrosion resistance are aluminum-zinc (AZ91, AZ60) and aluminum-manganese (AM50, AM60). The Mg-Al alloys, such as AZ91D and AM60B find application in the manufacturing of automotive components. Despite 
outstanding properties, the application of the Mg alloys in critical engineering is limited. The $\mathrm{Mg}$ alloys of $\mathrm{AZ}(\mathrm{Mg}-\mathrm{Al}-\mathrm{Zn})$ and $\mathrm{AM}(\mathrm{Mg}-\mathrm{Al}-\mathrm{Mn})$ series are the most cost-effective ones among the available limited choices; however, they exhibit low strength and low creep resistance at elevated temperature. They exhibit poor creep resistance properties above $125^{\circ} \mathrm{C}$, and hence cannot be used in automotive power-train, transmission-case, and engine-block components. The investigations revealed that the poor creep resistance exhibited by $\mathrm{Mg}$ - $\mathrm{Al}$ alloys at elevated temperatures is due to the dissolution of the $\mathrm{Mg}_{17} \mathrm{Al}_{12}$ phase. The additional alloying elements, such as calcium, strontium, rare earth elements, and silicon are introduced in $\mathrm{Mg}$ - $\mathrm{Al}$ alloys to suppress the formation of $\mathrm{Mg}_{17} \mathrm{Al}_{12}$ phase and to form other thermally stable phases at higher temperatures. The alloys used at higher temperatures are AE42, AE44, AS21, AS41, AJ62, and some other costly alloys. Some aluminum-free alloys like QE22 (containing silver with rare earth elements), WE43 (containing yttrium and other rare earth elements) are also used in higher temperature regions. The wrought magnesium alloys also find applications in automotive body parts like roof-pillars, front-end structures, and closures. The wrought magnesium alloys of rare earth elements $\mathrm{Gd}$ and/or, $\mathrm{Y}, \mathrm{Nd}$, Dy have been developed for higher temperature applications. The Mg-Gd-Y, Mg-Gd-Nd, and Mg-Gd-Dy alloy systems possess better specific strength and creep resistance than WE54 at both room and elevated temperatures. The precipitation process through heat treatment also enhances the properties of wrought products and is the area of further investigation. Interestingly, magnesium alloys developed through both casting and thermo-mechanical treatment involves costly rare earth elements [10-13]. Therefore, in order to fulfill industrial needs for wider applications, the development of novel magnesium alloys with better strength and creep resistance at lower costs is very necessary [14]. Tin (Sn) is a potential alloying element to develop low cost Mg-Sn alloys. $\mathrm{Sn}$ improves ductility and reduces cracking tendency of $\mathrm{Mg}$ alloys in forging [15]. Mg-Sn alloys show better corrosion resistance than pure magnesium $(\mathrm{Mg})$ and possess excellent mechanical properties and creep-resistance at high temperatures due to the presence of the $\mathrm{Mg}_{2} \mathrm{Sn}$ phase. The melting point of this intermetallic phase in $\mathrm{Mg}$-Sn alloys $\left(770^{\circ} \mathrm{C}\right)$ is much higher than that of the $\mathrm{Mg}_{17} \mathrm{Al}_{12}$ phase in $\mathrm{Mg}$-Al alloys $\left(462^{\circ} \mathrm{C}\right)[16,17]$. With these attributes, it is possible for $\mathrm{Mg}$-Sn alloys to be developed as creep resistant alloys. The study of Huang et al. [18] demonstrated that Sn precipitation in Mg-Sn alloys exhibited similar or better creep resistant property than AE42 alloys. Kang et al. [19] developed TAS831 (Mg-8Sn-3Al-1Si) Mg-Sn alloy, which showed creep properties better than AZ91, due to the formation of $\mathrm{Mg}_{2} \mathrm{Sn}$ and $\mathrm{Mg}_{2} \mathrm{Si}$ phases. Bowles and Abu Leil's works demonstrated that the incorporation of $\mathrm{Ca}$ in $\mathrm{Mg}$-Sn alloys largely improves the creep resistance of the $\mathrm{Mg}-\mathrm{Sn}$ alloys due to the formation of thermally stable $\mathrm{Mg}_{2} \mathrm{Ca}$ and $\mathrm{MgCaSn}$ phases $[20,21]$.

The addition of nanoparticles is another approach to improve the strength and ductility of $\mathrm{Mg}$ alloys. The addition of oxide nanoparticles $\left(\mathrm{Al}_{2} \mathrm{O}_{3}, \mathrm{Y}_{2} \mathrm{O}_{3}, \mathrm{TiO}_{2}, \mathrm{ZnO}, \mathrm{ZrO}_{2}\right.$, $\mathrm{Sm}_{2} \mathrm{O}_{3}$, and $\left.\mathrm{CeO}_{2}\right)$, carbides $\left(\mathrm{B}_{4} \mathrm{C}, \mathrm{SiC}\right.$, and $\left.\mathrm{TiC}\right)$, nitrides (TiN, $\mathrm{BN}$, and $\left.\mathrm{AlN}\right)$, borides $\left(\mathrm{SiB}_{6}, \mathrm{TiB}_{2}\right.$, and $\left.\mathrm{ZrB}_{2}\right)$, and $\mathrm{CNTs}$ can enhance the strength and ductility of Mg simultaneously [6]. The incorporation of thermally stable nanoparticles $\left(\mathrm{ZnO}, \mathrm{SiO}_{2}, \mathrm{Sm}_{2} \mathrm{O}_{3}\right.$, and $\mathrm{La}_{2} \mathrm{O}_{3}$ ) can also improve the ignition properties of $\mathrm{Mg}$. The incorporation of small percentage of $\mathrm{SiO}_{2}$ and $\mathrm{Sm}_{2} \mathrm{O}_{3}$ nanoparticles can improve the ignition temperature of $\mathrm{Mg}$ by $69{ }^{\circ} \mathrm{C}[22,23]$. The $\mathrm{Mg}-1.8 \mathrm{Y} / 1 \mathrm{CaO}$ nanocomposite fabricated by Tekumalla et al. [24] displayed the onset of ignition at $1045^{\circ} \mathrm{C}$. Ferkel et al. [25] fabricated $\mathrm{Mg}-3$ vol. $\% \mathrm{SiC}$ nanocomposite using powder metallurgy and hot extrusion and reported improvement in creep resistance, comparable or even better than creep resistant magnesium alloys (WE43, WE54, and QE22). Some other studies also demonstrated the improvement in creep properties of the magnesium based nanocomposites via grain boundary sliding obstruction, thermal expansion mismatch, load transfer from matrix to reinforcement, grain refinement, microstructural modifications including transformation of intermetallic in shape, size, and morphology [26,27]. In general, nanoparticles addition in existing Mg-based alloys could improve higher temperature properties, creep resistance, fatigue, ignition, machining, corrosion, and various other properties [28]. Graphene is an important new emerging 
nanoreinforcement since its isolation and characterization in 2004 by Geim and Novoselov. Graphene nanoplatelets (GNPs) is derivative of graphite and consists of multiple layers of graphene. It retains many appealing properties of single layer graphene and exhibits superior mechanical, thermal, electrical, and tribological properties [29,30]. GNPs has the potential to significantly improve the performance of different metals $(\mathrm{Mg}, \mathrm{Al}, \mathrm{Cu}$, $\mathrm{Fe}, \mathrm{Ni}$ ), alloys, and intermetallic compounds. Graphene-reinforced metal/alloy matrix composites manifest excellent mechanical, thermal, and electrical properties. In addition, GNPs can be produced on a large scale at a low cost. The proper dispersion of GNPs in the matrix is a crucial consideration to improve the performance of metal matrix composites (MMCs). The agglomeration of GNPs due to the Van der Waals force and the $\pi-\pi$ stacking effect creates a significant challenge during the processing of composites. Different $\mathrm{Mg}-\mathrm{Sn}$ alloys with improved mechanical properties and creep resistance have been fabricated by casting. However, conventional casting is not suitable to mix nanoparticles uniformly due to agglomeration issues. Powder metallurgy, melting and solidification, electrochemical deposition, thermal spraying, and other novel processing routes are generally used to fabricate graphene-based MMCs [31-34]. The powder metallurgy (PM) process is capable of dispersing a higher amount of nanoparticles, produces near-net size components, and has the ability to produce large batches of components for automotive applications. The process involves less complex steps, viz. mixing of metal powders and nanoparticles in desired composition by simple blending or mechanical alloying, consolidation of mixed powders, and sintering of consolidated components through resistance or microwave heating. Further, hot extrusion or equichannel angular extrusion is used for the porosity reduction and grain refinement of the components. The PM is an economical process, consumes lesser time, and generates lesser scrap. There are some studies in the literature by various research groups involving powder metallurgy for the fabrication of graphenereinforced Mg-based nanocomposites [35]. Rashad et al. [36] reported an improvement in the mechanical properties of pure $\mathrm{Mg}$ and $\mathrm{Mg}-1 \mathrm{Al}-1 \mathrm{Sn}$ alloy after the incorporation of a low amount of GNP (0.18-0.3 wt.\%). Khurram Munir et al. [37] fabricated Mg-GNP MMCs with different graphene contents $(0.1,0.2$, and $0.3 \mathrm{wt} . \%)$ and obtained positive results in terms of compression, corrosion, and biocompatibility. Kumar et al. [30] fabricated Mg-3Al/ $x$ GNP $(x=0.1,0.3$, and $0.5 \mathrm{wt} . \%)$ alloy-nanocomposites with improved mechanical and tribological properties. The incorporation of GNP improved coefficient of thermal expansion (CTE) (owing significant CTE difference between $\mathrm{Mg}$ and GNP) and ignition characteristics of the nanocomposites. The graphitic nature of GNP helped the nanocomposite to improve wear performance. The role of reinforcement amount of GNP has been also observed in the properties of the fabricated composites. The increasing amount of GNP improves the properties, but after a certain limit, agglomeration of GNP takes place, which affect the properties negatively.

The results of the literature search indicate that no work has been conducted so far using GNP in aluminum free magnesium alloys. Accordingly, in the present study, pure $\mathrm{Mg}$, Mg-3Sn alloy (in wt.\%), and Mg-3Sn + 0.2 GNP alloy-nanocomposites (in wt.\%) were fabricated through powder metallurgy followed by hot extrusion. The effects of GNP (in low content) and alloying element tin on the microstructural and mechanical properties of magnesium were critically investigated.

\section{Materials and Methods}

\subsection{Materials}

Magnesium powder (60-300 $\mu \mathrm{m})$ from Merck, Germany, tin powder (99.9\% pure, $45 \mu \mathrm{m}$ ) from Goodfellow Cambridge Limited, Huntingdon, UK, graphene nanoplatelets (thickness $=6-10 \mathrm{~nm}$ and width $=15 \mu \mathrm{m}$ ) from Tokyo Chemical Industry Co. Ltd., Tokyo, Japan were used as raw materials. The Mg:Sn ratio in the alloy was 97:3 (in wt.\%), and the $\mathrm{Mg}-\mathrm{Sn}+\mathrm{GNP}$ ratio in the alloy-nanocomposite was 97:3 + 0.2 (in wt.\%). 


\subsection{Synthesis}

Pure bulk Mg, Mg-3Sn alloy, and Mg-3Sn + 0.2 GNP alloy-nanocomposite were synthesized by powder metallurgy. $\mathrm{Mg}$, Sn, and GNP powders were mixed at different ratios, and no process control agent was used during mixing. Except for pure $\mathrm{Mg}, \mathrm{a}$ Turbula ${ }^{\circledR}$ T 2 F mixer (Make: Willy A. Bachofen AG, Muttenz, Switzerland) rotated at $50 \mathrm{rpm}$ for one hour was used for the homogeneous mixing of Sn and GNPs. Rubber mold with an inner diameter of $50 \mathrm{~mm}$ was filled with the powder mixtures up to a height of $80 \mathrm{~mm}$ under continuous tapping. The rubber mold was then subjected to cold isostatic compression under a water pressure of $370 \mathrm{MPa}$. The schematic of the compression of powder is shown in Figure 1.

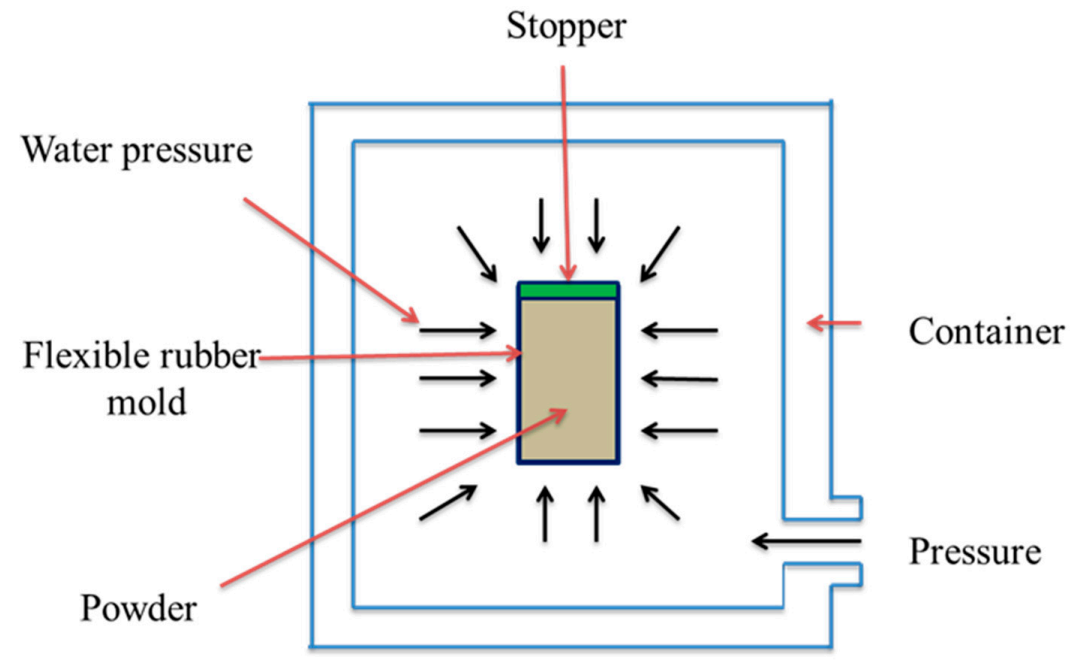

Figure 1. Schematic of cold isostatic compression of powder.

The green compacts were sintered in a high-temperature sintering furnace (Xerion Advanced Heating ${ }^{\circledR}$ Ofentechnik $\mathrm{GmbH}$, Berlin, Germany) at $500{ }^{\circ} \mathrm{C}$ for two hours under an argon atmosphere. The sintering scheme is shown in Figure 2. The sintered billets were then machined to a size of $35 \mathrm{~mm}$ (diameter) $\times 40 \mathrm{~mm}$ (height). The resultant machined billets were homogenized at $400{ }^{\circ} \mathrm{C}$ for one hour and then hot extruded at $350{ }^{\circ} \mathrm{C}$. The extrusion ratio was set to $20.25: 1$ to produce $8-\mathrm{mm}$ diameter rods. Figure 3 shows the images of sintered billets and the extruded rods of the samples.

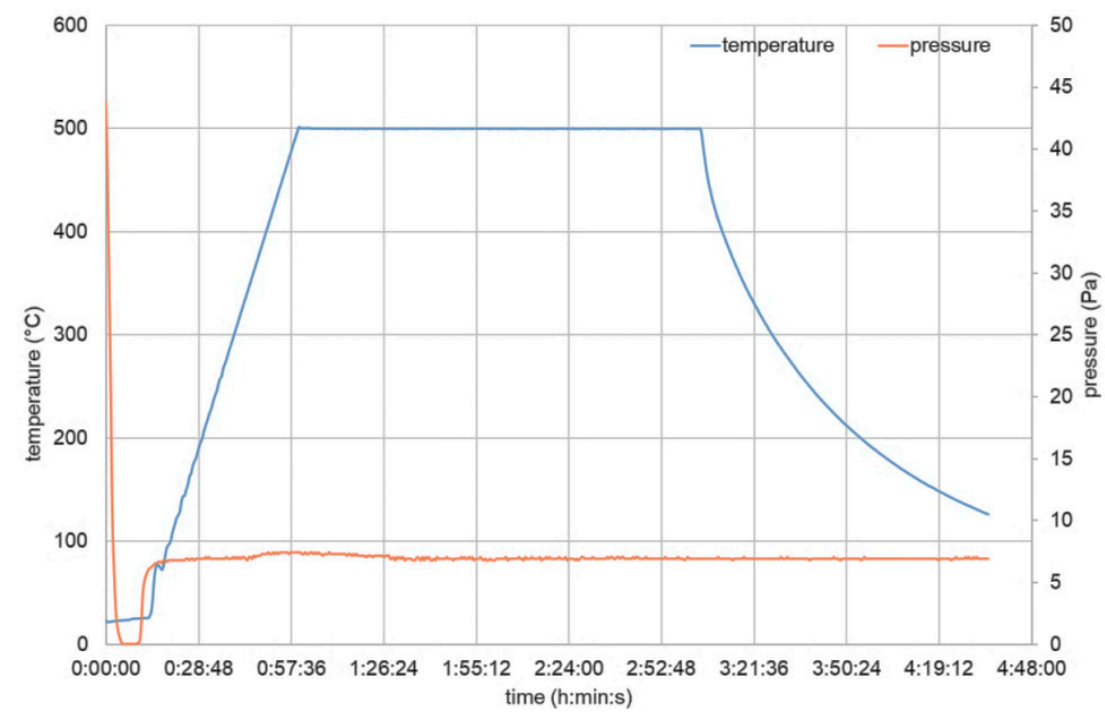

Figure 2. Sintering scheme for $\mathrm{Mg}-3 \mathrm{Sn}+0.2 \mathrm{GNP}$ compacts. 


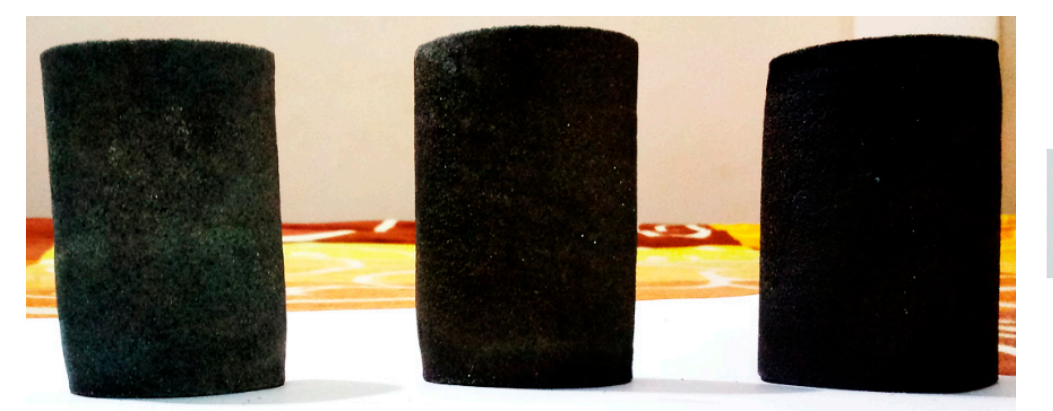

(a)

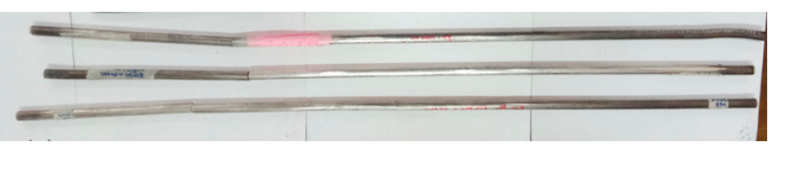

(b)

Figure 3. Images of (a) sintered billets and (b) extruded rods.

\subsection{X-ray Diffraction Analysis}

The $\mathrm{X}$-ray diffraction analysis of the extruded samples was performed in an automated Shimadzu LAB-XRD-6000 ( $\mathrm{Cu} \mathrm{K} \alpha ; \lambda=1.54 \AA$, Shimadzu Corporation, Kyoto, Japan) spectrometer with a scan rate of $2^{\circ} / \mathrm{min}$. The phases present in the samples were analyzed from the intensities of $\mathrm{X}$-ray diffraction peak.

\subsection{Density and Porosity Measurement}

The theoretical densities of the samples were obtained by the rule-of-mixture, and the experimental densities of the bulk samples were estimated by Archimedes' principle [38]. The bulk samples of each composition were weighed in air and water with the help of a weighing machine (Model: PRACTUM213-10IN, Germany; accuracy $=0.0001 \mathrm{~g}$ ). The theoretical densities of $\mathrm{Mg}$, Sn, and GNP were considered as $1.74 \mathrm{~g} \cdot \mathrm{cm}^{-3}, 7.28 \mathrm{~g} \cdot \mathrm{cm}^{-3}$, and $2.30 \mathrm{~g} \cdot \mathrm{cm}^{-3}$, respectively. The theoretical densities of the samples were calculated assuming dense and no interfacial reaction between the constituents of the nanocomposites. The porosity of the samples was evaluated assuming difference in theoretical and experimental densities due to porosity in the samples. Average reading of five samples for each composition was considered as final measurement.

\subsection{Microhardness Test}

The microhardness values of the samples were measured by an MTR3/50-50/NI machine equipped with Tribotester software (MICROTEST S.A., Madrid, Spain). The samples were cut from the middle portion of the extruded rods and then made flat and polished to perform indentation tests. A load of $5 \mathrm{~N}$ was applied by an indenter with a loading rate of $5 \mathrm{~N} / \mathrm{min}$ followed a dwell period of $30 \mathrm{~s}$. A Vickers pyramidal diamond indenter with a phase angle of $136^{\circ}$ was used for indentation tests. Five indentations at different places were made for each sample to avoid discrepancies in the obtained results.

\subsection{Microstructural Characterization}

The field-emission scanning electron microscopy (FESEM) images of GNPs, the elemental area mapping of different samples, the identification of the $\mathrm{Mg}_{2} \mathrm{Sn}$ phase in the composite, and the morphologies of fracture surfaces after tensile and compressive tests were obtained using Carl Zeiss Supra FESEM (Zeiss, Oberkochen, Germany).

\subsection{Tensile Test}

Tensile tests of the extruded samples were performed on a Tinius Olsen (H50KS, Horsham, PA, USA) mechanical testing machine with a strain rate of $1.6 \times 10^{-4} \mathrm{~s}^{-1}$. Dogbone-shaped tensile specimens with a gauge diameter of $4 \mathrm{~mm}$ and a gauge length of $20 \mathrm{~mm}$ were prepared from 8-mm extruded rods according to the ASTM E8/E8M-13a standard. The samples were machined using a CNC lathe machine (MSME Tool Room, Kolkata, India) and then polished to remove uneven surfaces. A minimum of three tests 
were performed for each sample to ensure reliability of the results. Fractography was performed in the tensile fracture samples using FESEM to study possible modes of failures.

\subsection{Compression Test}

Compression tests were performed on a Hounsfield mechanical testing machine (H50KS) according to the ASTM E9-09 standard. The tests were carried out on the extruded cylindrical samples of 7-mm diameter and 7-mm length. The strain rate was set to $8.3 \times 10^{-5} \mathrm{~s}^{-1}$. Five tests were conducted for each sample to ensure the consistency of the results. Fractography was also done on compressive fracture surfaces of the samples to get a better understanding of possible modes of failures.

\section{Results}

\subsection{Density Measurement}

Pure bulk Mg, Mg-3Sn alloy, and Mg-3Sn + 0.2 GNP alloy-nanocomposite were successfully synthesized using powder metallurgy technique followed by hot extrusion. The densities and porosities of the bulk extruded samples of three compositions are reported in Table 1.

Table 1. Density (g/cc) measurements of pure Mg, Mg-3Sn alloy, and Mg-3Sn + 0.2 GNP nanocomposite.

\begin{tabular}{cccc}
\hline Material & Theoretical Density & Experimental Density & Porosity (\%) \\
\hline $\mathrm{Mg}$ & 1.740 & $1.707 \pm 0.0040$ & 1.90 \\
$\mathrm{Mg}-3 \mathrm{Sn}$ & 1.781 & $1.766 \pm 0.0028$ & 0.84 \\
$\mathrm{Mg}-3 \mathrm{Sn}+0.2 \mathrm{GNP}$ & 1.782 & $1.765 \pm 0.0017$ & 0.95 \\
\hline
\end{tabular}

\subsection{XRD Analysis}

Figure 4 presents the X-ray diffraction line profile of the extruded samples of pure $\mathrm{Mg}$, Mg-3Sn alloy, and Mg-3Sn + 0.2 GNP alloy-nanocomposite. The peaks indicate different crystalline phases.

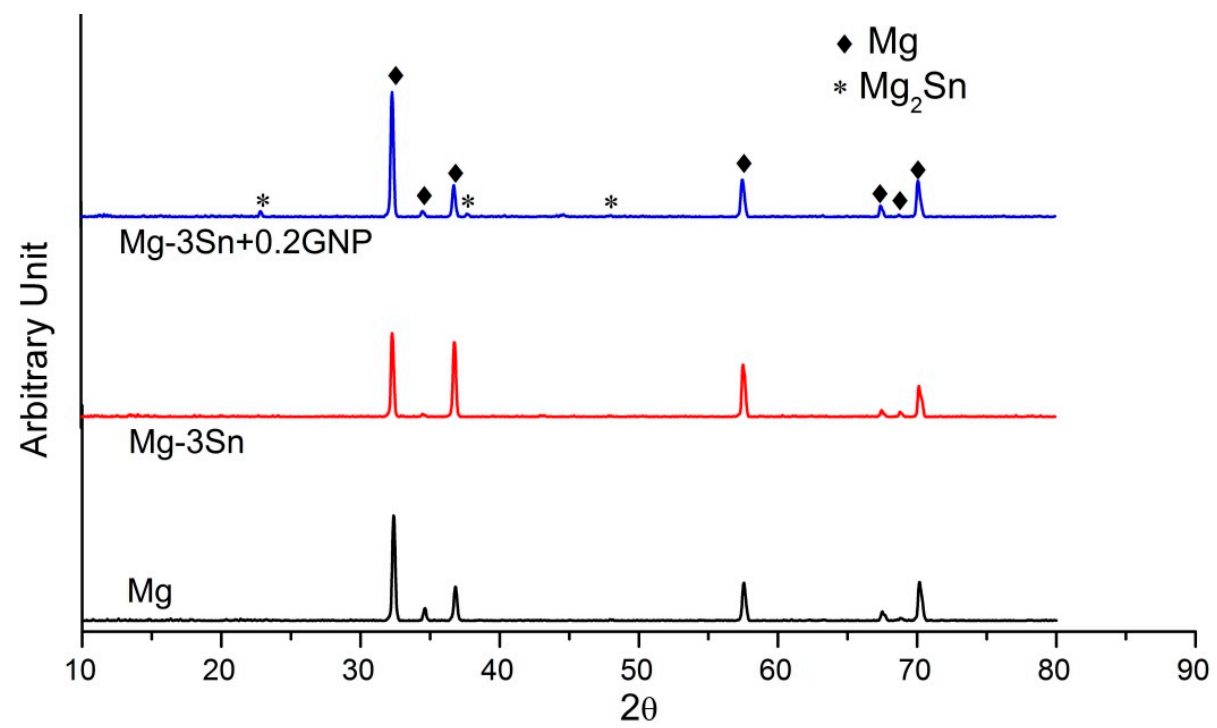

Figure 4. XRD results of extruded samples of pure $\mathrm{Mg}, \mathrm{Mg}-3 \mathrm{Sn}$ alloy, and $\mathrm{Mg}-3 \mathrm{Sn}+0.2 \mathrm{GNP}$ nanocomposite.

\subsection{Microstructural Analysis}

Figure 5a shows the FESEM image of the graphene nanoplatelets along with optical image of graphene powder as inset. It could be seen that the graphene sheets are exfoliated, resembled a loose sponge like structure. The ultrathin crumpled layer platelets were visible 
to the electron beam. The Raman spectroscopic analysis of as received GNPs is presented in Figure 5b. It can be seen that the D band (related to disorder) of GNPs displays at $1332 \mathrm{~cm}^{-1}$. The $\mathrm{G}$ band (related to graphite) exhibited at $1581 \mathrm{~cm}^{-1}$ with much higher intensity as compared to $\mathrm{D}$ band. The second order $2 \mathrm{D}$ band appeared at $2681 \mathrm{~cm}^{-1}$. The intensity ratio of $2 \mathrm{D}$ Band to $\mathrm{G}$ band $\left(\mathrm{I}_{2 \mathrm{D}} / \mathrm{I}_{\mathrm{G}}\right)$ indicated the multilayer feature of graphene. The presence of the polygonal and lathe-shaped $\mathrm{Mg}_{2} \mathrm{Sn}$ phase in the $\mathrm{Mg}-3 \mathrm{Sn}+0.2 \mathrm{GNP}$ nanocomposite was confirmed by FESEM (Figure 6) [39,40] image analysis. The FESEMEDX (Energy Dispersive X-Ray Analysis elemental) area mapping in Figure 7 reveals that a small cluster of GNPs was evenly distributed in the alloy matrix and acted as a grain nucleation agent to pin the grain boundary.

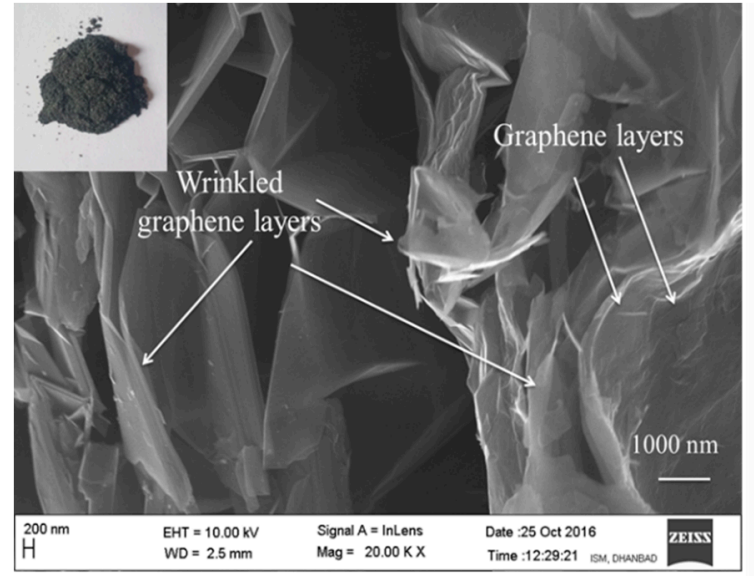

(a)

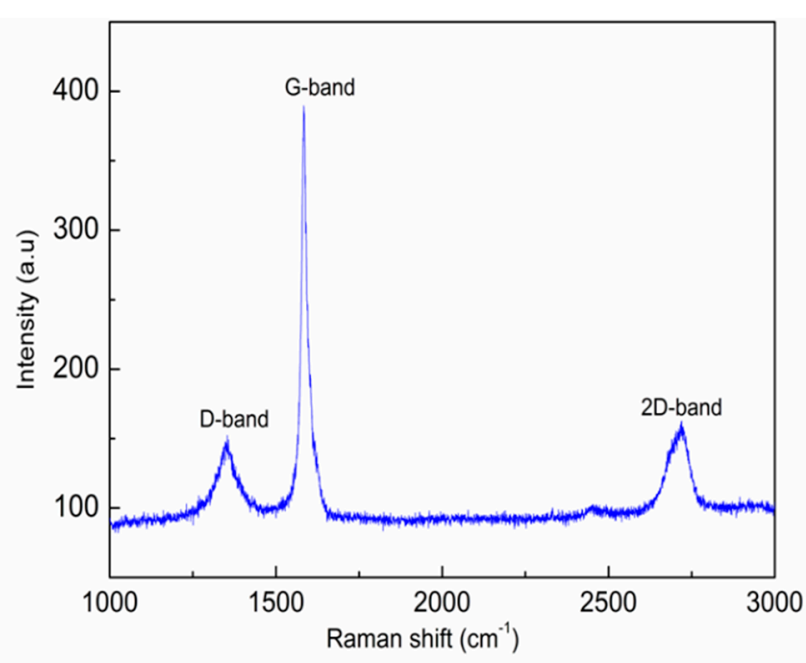

(b)

Figure 5. (a) High magnification field-emission scanning electron microscopy (FESEM) image of the graphene nanoplatelets (GNP) and (b) Raman spectra of GNP.

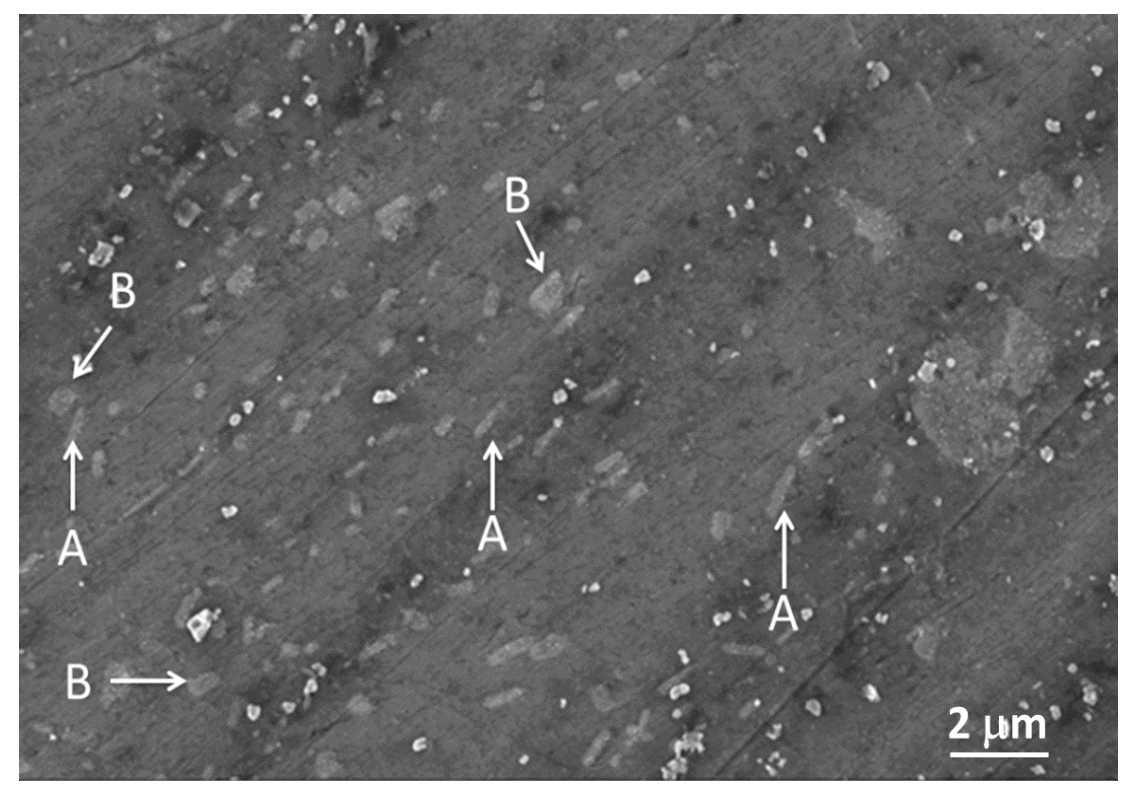

Figure 6. FESEM morphology of $\mathrm{Mg}_{2} \mathrm{Sn}$ phase in the form of lathe/rod (A) and polygon (B) in the $\mathrm{Mg}-3 \mathrm{Sn}+0.2 \mathrm{GNP}$ alloy-nanocomposite. 


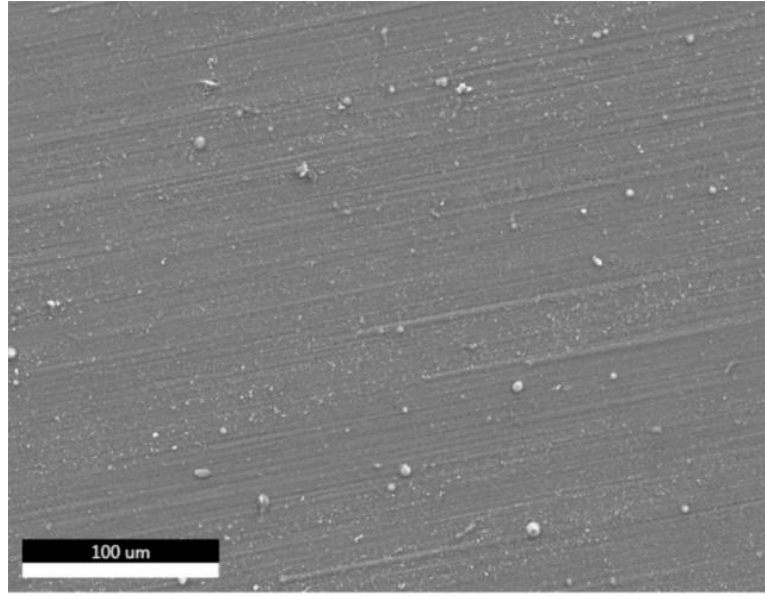

(a)

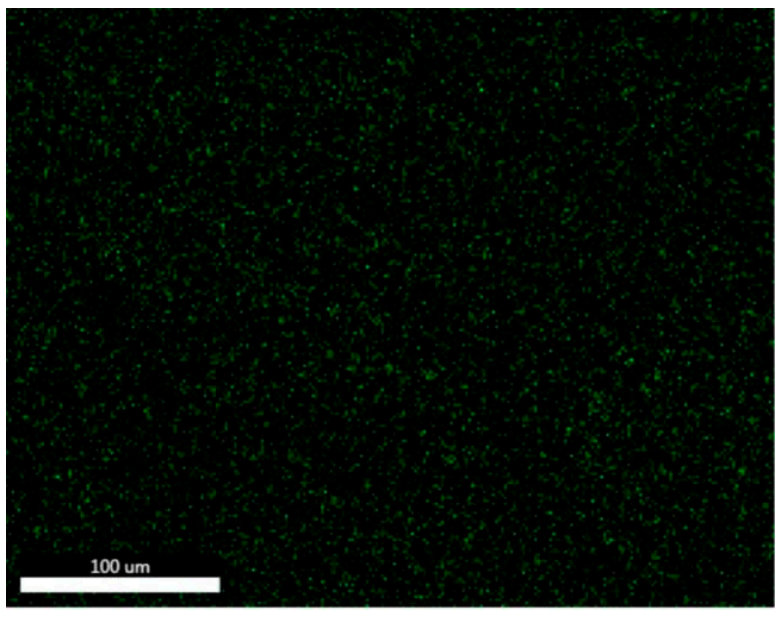

(c)

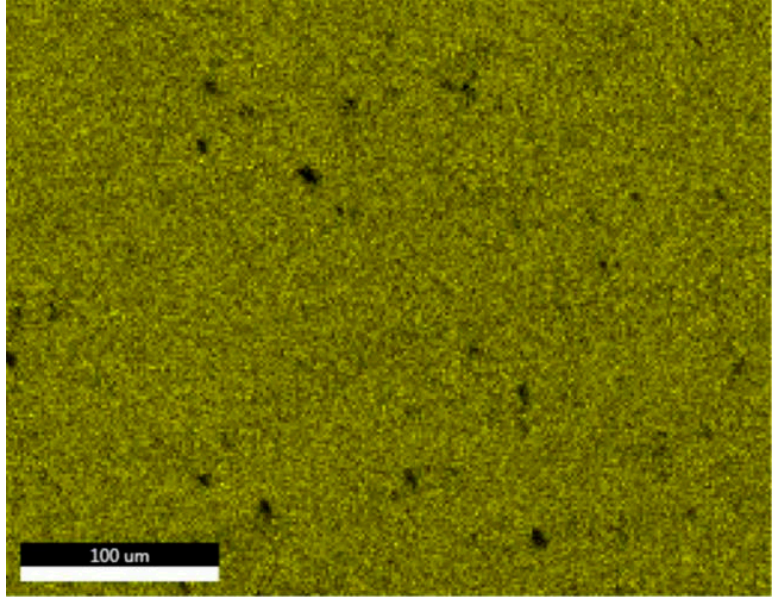

(b)

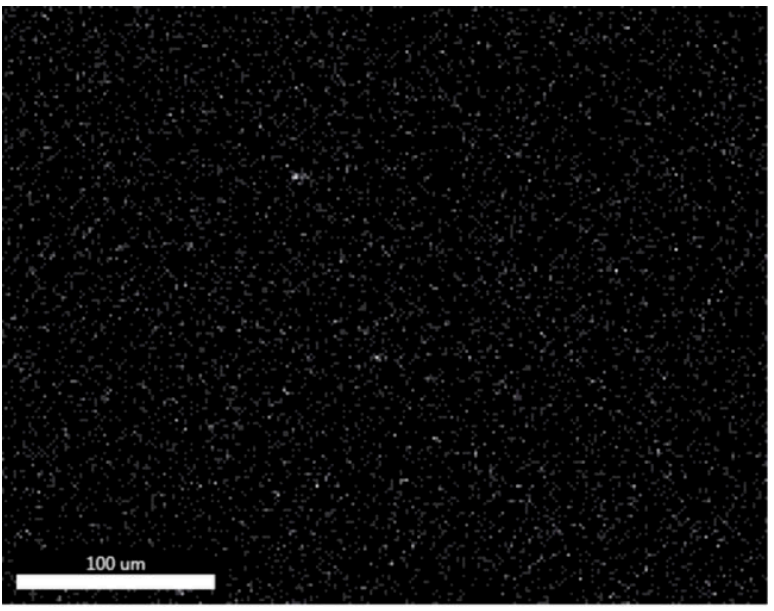

(d)

Figure 7. FESEM-EDX elemental area mapping of the Mg-3Sn + 0.2 GNP nanocomposite: (a) FESEM image of a selected area, (b) $\mathrm{Mg}$, (c) Sn, and (d) Carbon (GNP).

\subsection{Microhardness and Tensile Properties}

Table 2 presents the Vickers microhardness values and tensile properties of the three samples.

Table 2. Micro-hardness and tensile properties at room temperature $\left(24^{\circ} \mathrm{C}\right)$.

\begin{tabular}{|c|c|c|c|c|}
\hline Material & $\begin{array}{c}\text { Vicker's Hardness } \\
\text { (HV) }\end{array}$ & $\begin{array}{c}0.2 \% \text { Offset Yield } \\
\text { Strength }\left(\mathrm{Nmm}^{-2}\right)\end{array}$ & $\begin{array}{l}\text { Ultimate Tensile } \\
\text { Strength }\left(\mathrm{Nmm}^{-2}\right)\end{array}$ & Failure Strain (\%) \\
\hline $\mathrm{Mg}$ & $38 \pm 4$ & $82 \pm 3$ & $151 \pm 3$ & $17.9 \pm 0.7$ \\
\hline $\mathrm{Mg}-3 \mathrm{Sn}$ & $50 \pm 4$ & $132 \pm 11$ & $185 \pm 10$ & $21.3 \pm 2.2$ \\
\hline $\mathrm{Mg}-3 \mathrm{Sn}+0.2 \mathrm{GNP}$ & $54 \pm 3$ & $136 \pm 21$ & $201 \pm 7$ & $21.8 \pm 1.6$ \\
\hline
\end{tabular}

Figure 8a displays the tensile engineering stress-strain curves of the three different samples at room temperature $\left(24^{\circ} \mathrm{C}\right)$. The corresponding tensile specimens before and after the tests are presented in Figure $8 b$. 


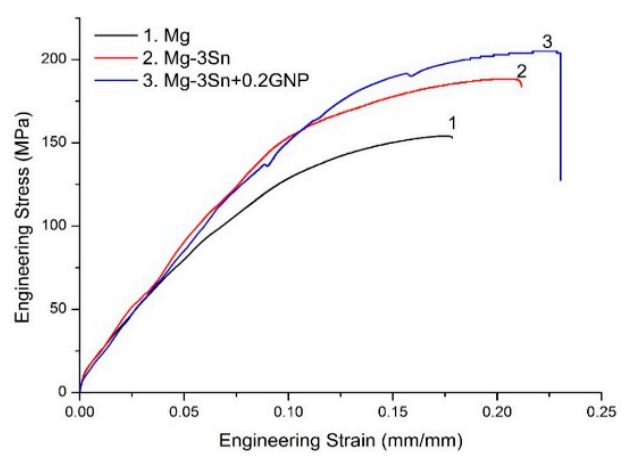

(a)

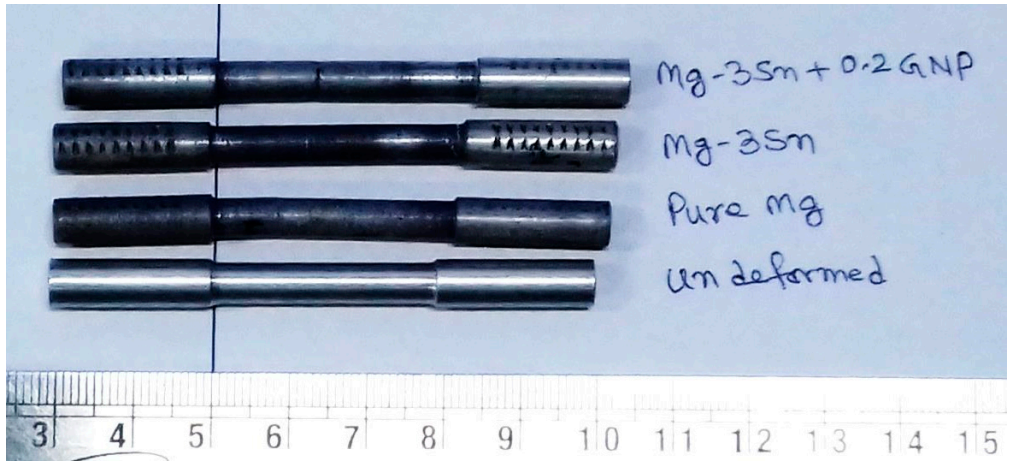

(b)

Figure 8. Tensile behavior of pure $\mathrm{Mg}$, Mg-3Sn alloy, and $\mathrm{Mg}-3 \mathrm{Sn}+0.2 \mathrm{GNP}$ composite: (a) representative tensile engineering stress-strain curve and (b) corresponding images of undeformed and deformed tensile samples.

Table 3 presents the room-temperature compressive properties of all three compositions. Figure $9 \mathrm{i}$ shows the behavior of engineering compressive stress-strain curves at room temperature $\left(24^{\circ} \mathrm{C}\right)$. The corresponding compressive specimens before and after the tests are presented in Figure 9ii.

Table 3. Compressive properties at room temperature $\left(24^{\circ} \mathrm{C}\right)$.

\begin{tabular}{cccc}
\hline Material & $\begin{array}{c}\mathbf{0 . 2} \% \text { Offset Yield } \\
\left.\text { Strength } \mathbf{( N m m}^{-\mathbf{2}}\right)\end{array}$ & $\begin{array}{c}\text { Ultimate Compressive } \\
\text { Strength } \mathbf{( N m m}^{-2} \text { ) }\end{array}$ & Failure Strain (\%) \\
\hline $\mathrm{Mg}$ & $115 \pm 8$ & $341 \pm 11$ & $23.3 \pm 0.8$ \\
$\mathrm{Mg}-3 \mathrm{Sn}$ & $138 \pm 14$ & $409 \pm 24$ & $24.6 \pm 1.5$ \\
$\mathrm{Mg}-3 \mathrm{Sn}+0.2 \mathrm{GNP}$ & $159 \pm 9$ & $453 \pm 19$ & $25 \pm 1.1$ \\
\hline
\end{tabular}

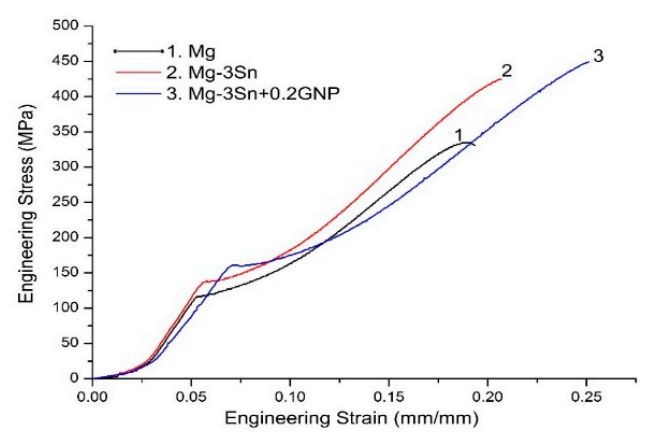

(i)

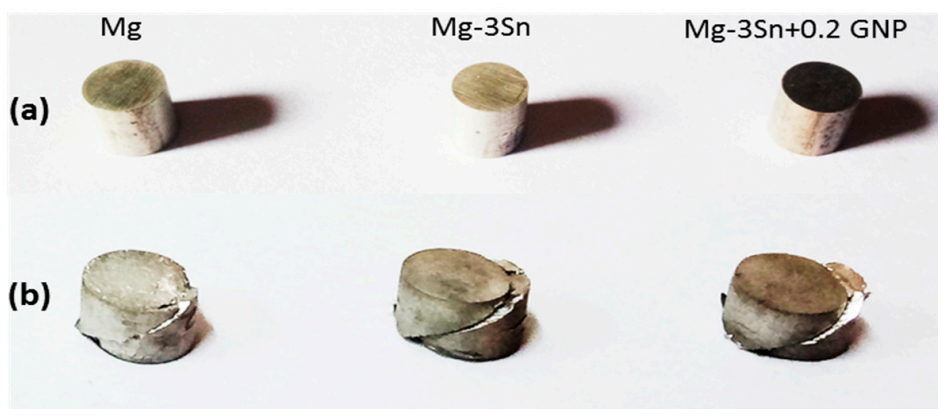

(ii)

Figure 9. Compressive behavior of pure $\mathrm{Mg}, \mathrm{Mg}-3 \mathrm{Sn}$ alloy, and $\mathrm{Mg}-3 \mathrm{Sn}+0.2 \mathrm{GNP}$ composite: (i) representative compressive engineering stress-strain curve and (ii) corresponding images of undeformed and deformed samples.

\section{Discussion}

The present alloy nanocomposites were formed by solid-state fabrication process. The final bonding of matrix metal and the dispersed graphene occurred due to mechanical interlocking and diffusion. During sintering, the presence of graphene in $\mathrm{Mg}$-Sn alloy matrix reduced the coefficients of thermal expansion (CTEs) of the composites that may have had a significant role of shear lag and thermally activated dislocation mechanism in strengthening the present Mg-based composites. Furthermore, the interface between the alloy and graphene can effectively restrict the dislocation movement during the deformation process. The graphene alignment parallel to the loading axis may be one of the mechanisms to enhance the strength due to more load transfer during tensile loading. To investigate the role of the graphene in alloy matrix, a theoretical calculation and a FEM-based 3D 
meso-model were demonstrated by Peng et al. [41]. In their model, the nanocomposite exhibited higher strength as compare to the Sn-Bi alloy.

\subsection{Density Analysis}

An almost negligible amount of variation between the theoretical and experiment densities was observed. These results suggested the extruded samples were nearly dense. The alloy and composites samples exhibited less porosity as compared to pure $\mathrm{Mg}$ sample. This result attributed good interfacial bonding between the matrix and the nano-reinforcement.

\subsection{XRD Results Analysis}

The results reveal that the $\alpha-\mathrm{Mg}$ phase was present in both the Mg-3Sn alloy and the Mg-3Sn + 0.2 GNP alloy-nanocomposite. The absence of the Sn peak indicated the formation of a solid solution of pure $\mathrm{Mg}$ and $\mathrm{Sn}$. Due to the addition of a very small amount of GNPs in the Mg matrix, the peak intensities of GNPs were almost invisible. A similar observation was reported by Chen et al. [17]. Some of the peaks of $\mathrm{Mg}_{2} \mathrm{Sn}$ with lower intensities were observed in the XRD pattern.

\subsection{Microhardness and Tensile Properties Analysis}

It can be seen that after the addition of Sn and GNP, the room-temperature mechanical properties of the Mg-3Sn + 0.2 GNP nanocomposite were invariably improved. The microhardness of the Mg-3Sn $+0.2 \mathrm{GNP}$ alloy-nanocomposite was improved by $7.8 \%$ and $22.4 \%$ with respect to those of the Mg-3Sn alloy and pure $\mathrm{Mg}$, respectively. The microhardness of the $\mathrm{Mg}-3 \mathrm{Sn}$ alloy was $\sim 32 \%$ higher than that of pure $\mathrm{Mg}$. It happened because the alloying element $\mathrm{Sn}$ formed the $\mathrm{Mg}_{2} \mathrm{Sn}$ phase, which is more thermally and mechanically stable and contributed to precipitation hardening and dispersion hardening. Further addition of the harder reinforcement (GNP) caused dispersion hardening and hindered dislocation mobility through the suppression of recrystallization and crystal grain growth [42]. The ultimate tensile strength of the alloy-nanocomposite was $8.8 \%$ and $33.5 \%$ greater than those of the alloy and pure $\mathrm{Mg}$, respectively.

The unique two-dimensional geometry of GNP contributes in the improvement of the mechanical properties of the nanocomposite. During processing of the composite, structural changes happens in GNP in form of exfoliation, layers stacking, and re-agglomeration, subsequently agglomeration of defects via impact and friction while interacting with neighboring GNPs, tailors the mechanical performance of the composites. Recently, Ahmad et al. [43] displayed wrapping and anchor-type interlocking of GNP and metal matrix, which hindered pulling out of GNP from the matrix. During loading, load is transferred from the matrix to outer layer of GNP. The layers behave elastically and transfer the loads to the inner layers, which do not come out due to matrix grain anchoring. The Zener pinning by GNP reinforcement induced microstructural refinement contributed to the simultaneous enhancement of strength and hardness [44]. The strengthening of the $\mathrm{Mg}-3 \mathrm{Sn}$ matrix was associated with the load transfer from the $\mathrm{Mg}$ matrix to $\mathrm{Mg}_{2} \mathrm{Sn}$ and GNPs, the increased dislocation density due to thermal expansion coefficient (CTE) mismatch and elastic modulus mismatch, Orowan looping, and solid solution strengthening [45]. The prismatic punching of dislocation at the interface of the alloy matrix and GNP nanoparticles resulted in work hardening due to the CTE mismatch. The CTE mismatch between the Mg3Sn alloy matrix and GNPs promoted the wrinkling effect in GNPs and further hindered dislocation movements [46]. The elastic modulus mismatch between the alloy matrix and GNPs generated dislocations due to inhomogeneous slips. Saba et al. [47] reported that the elastic modulus difference between the matrix and reinforcement particles improved the strength of the composite during work hardening by enhancing interfacial bonding. The $\mathrm{Mg}_{2} \mathrm{Sn}$ phase in the Mg-3Sn alloy and GNPs in the Mg-3Sn + 0.2 GNP alloy-nanocomposite acted as obstacles and improved the strength by Orowan looping. Residual dislocation loops were formed around precipitates after dislocations bowed out and bypassed them, resulting in a higher work hardening effect under the applied load. The ductility of the 
Mg-3Sn alloy was higher than that of pure $\mathrm{Mg}$, and the further addition of $0.2 \mathrm{wt} . \% \mathrm{GNP}$ improved the ductility of Mg-3Sn + 0.2 GNP. The failure strain of Mg-3Sn + 0.2 GNP was enhanced by 2.3 and $21.8 \%$ with respect to those of the Mg-3Sn alloy and pure $\mathrm{Mg}$, respectively. Figure 10 presents the fracture surface morphologies of the tensile samples. The fracture surface morphology of pure $\mathrm{Mg}$ featured brittle failure due to a limited number of slip systems clearly showing microscopically small rough cleavages and steps. The fracture surface morphology of Mg-3Sn and Mg-3Sn + 0.2 GNP featured ductile failure as dimples and tear ridges were formed on the surface through a void-sheet mechanism. Intergranular crack propagation was also noticed in the alloy.

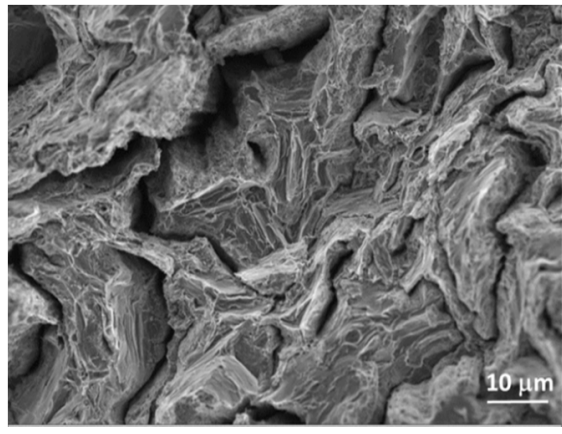

(a)

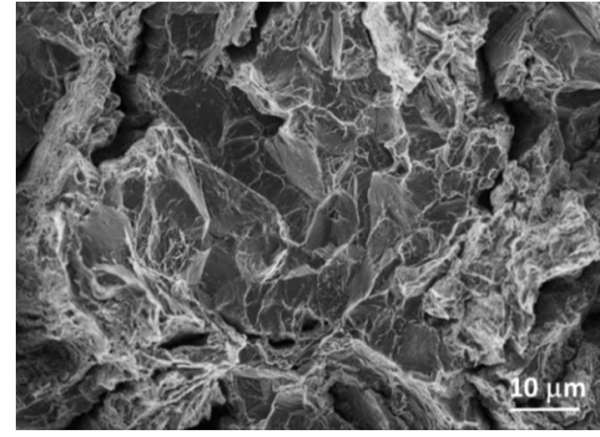

(b)

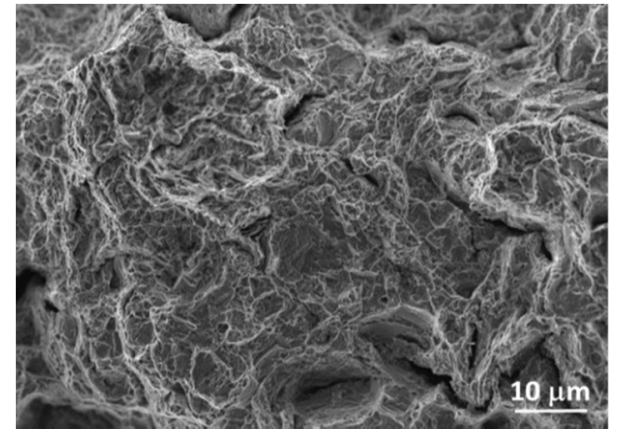

(c)

Figure 10. Fracture surface morphology of tensile failure samples: (a) Mg, (b) Mg-3Sn, and (c) Mg-3Sn + 0.2 GNP.

\subsection{Compressive Properties Analysis}

The compressive strength of Mg-3Sn + 0.2 GNP was improved by 10.7 and $32.9 \%$ with respect to the Mg-3Sn alloy and pure $\mathrm{Mg}$, respectively, without compromising the failure strain. Figure 11 presents the surface fracture morphologies of the compressed samples. The presence of a shear band on the fracture surfaces of all samples indicated shear failure. The fracture surface in the Mg-3Sn + 0.2 GNP composite was observed to be smooth and the presence of less micro crack as compared to pure $\mathrm{Mg}$ and alloy. An improvement in compressive ductility was noticed after the addition of nano-GNPs [11,48]. An activation of non-basal slip through grain refinement occurred after the addition of GNPs in the alloy matrix. The activation of non-basal slip could improve the deformation behavior under tensile loading by weakening the basal texture, which was preferentially aligned in hot-extruded Mg materials along the extrusion direction [49]. The deformation of Mg-based materials under compressive loading along the extrusion direction occurs through twinning, followed by slip [50]. Under compressive loading, failure strain is normally reduced due to the presence of the second phase, which hinders the twinning process. No significant change in failure strain occurred due to the compensating effect of $\mathrm{Mg}_{2} \mathrm{Sn}$ and GNPs was observed in the present study.

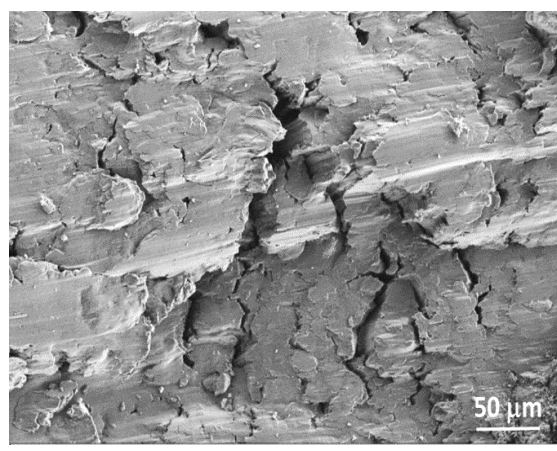

(a)

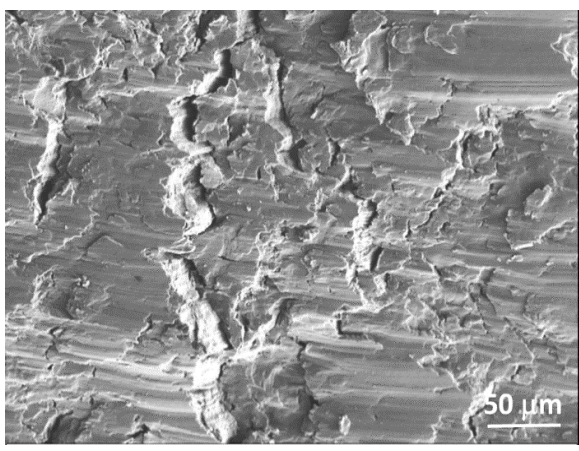

(b)



(c)

Figure 11. Fracture surface morphology of compressive failure samples: (a) Mg, (b) Mg-3Sn, and (c) Mg-3Sn $+0.2 \mathrm{GNP}$. 


\section{Conclusions}

Pure bulk Mg, Mg-3Sn alloy, and Mg-3Sn + 0.2 GNP alloy-nanocomposite were fabricated by powder metallurgy assisted by sintering in an inert atmosphere. The effects of Sn and GNP addition on mechanical and microstructural properties were studied. The main observations are presented below.

1. The microhardness of the Mg-3Sn alloy was improved by $22.4 \%$ with respect to that of pure Mg. The microhardness of the Mg-3Sn + 0.2 GNP was improved by 42.4 and $7.8 \%$ with respect to those of pure $\mathrm{Mg}$ and the $\mathrm{Mg}-3 \mathrm{Sn}$ alloy, respectively. This can be attributed to obstruction in dislocation movement in the presence of harder intermetallic $\mathrm{Mg}_{2} \mathrm{Sn}$ phase and GNP.

2. The ultimate tensile strength of the Mg-3Sn alloy was improved by $22.5 \%$ with respect to that of pure $\mathrm{Mg}$. The ultimate tensile strength of $\mathrm{Mg}-3 \mathrm{Sn}+0.2 \mathrm{GNP}$ was improved by 33.5 and $9 \%$ with respect to those of pure $\mathrm{Mg}$ and the $\mathrm{Mg}-3 \mathrm{Sn}$ alloy, respectively. The percentage failure strain of the nanocomposite was improved by 21.8 and $19 \%$ with respect to those of pure $\mathrm{Mg}$ and $\mathrm{Mg}-3 \mathrm{Sn}$ alloy.

3. The ultimate compressive strength of the Mg-3Sn alloy was improved by $20 \%$ with respect to that of pure $\mathrm{Mg}$. The ultimate compressive strength of Mg-3Sn + 0.2 GNP was improved by 32.9 and $10.7 \%$ with respect to those of pure $\mathrm{Mg}$ and the $\mathrm{Mg}-3 \mathrm{Sn}$ alloy, respectively without compromising failure strain. No significant changes were observed in the ductility.

4. After the addition of $0.2 \% \mathrm{GNP}$ in the Mg-3Sn alloy, the improvement in the tensile strength $(+16.6 \mathrm{MPa})$ of the Mg-3Sn + 0.2 GNP alloy-nanocomposite was lower than that of the compressive strength $(+43.7 \mathrm{MPa})$. However, the nanocomposite possessed good value of ultimate tensile strength of $201 \mathrm{MPa}$ and ultimate compressive strength of $453 \mathrm{MPa}$. This improvement in the properties can be ascribed to CTE mismatch, elastic modulus mismatch, load transfer mechanism, and Orowan strengthening.

The present study displays the improved room temperature micro-hardness, tensile, and compressive characteristics of the Mg-3Sn + 0.2 GNP nanocomposite. The results are promising for wide spread applications of such materials in automobiles, aircraft, consumer electronics, and sports sectors. However, further study is required to investigate high-temperature mechanical properties, thermal properties, creep, fatigue, wear, damping, and corrosion to meet the requirements of automobile, aerospace, defense, etc.

Author Contributions: A.M. and K.S. proposed the original project and designed the experimental investigations; P.K. carried out the experiments with the assistance of T.C. and J.J.; P.K. analyzed the data and wrote the draft paper. Some parts of the experiments were carried out in the Department of Mechanical Engineering under the guidance of M.G.; A.M. prepared the final manuscript. The technical comments, analyses and interpretation of M.G. are greatly appreciated. All authors have read and agreed to the published version of the manuscript.

Funding: The authors would like to acknowledge Ministry of Education Tier 2 Funding, Singapore (WBS\# R265-000-622-112) for the financial support in carrying out this research work.

Acknowledgments: The authors gratefully acknowledge the Department of Science \& Technology, Government of India (project no.: SB/EMEQ-020/2013) for providing materials and MTR3/50-50/NI machine (MICROTEST S. A., Spain) in which hardness tests were performed. The authors thank the reviewers for their careful reading of the manuscript and their many insightful comments and suggestions to improve the manuscript.

Conflicts of Interest: The authors declare no conflict of interest.

\section{References}

1. Kainer, K.U. (Ed.) Magnesium Alloys and Technology; John Wiley \& Sons: Hoboken, NJ, USA, 2003.

2. Xu, W.; Birbilis, N.; Sha, G.; Wang, Y.; Daniels, J.E.; Xiao, Y.; Ferry, M. A high-specific-strength and corrosion-resistant magnesium alloy. Nat. Mater. 2015, 14, 1229-1235. [CrossRef] [PubMed]

3. Mallick, A.; Vedantam, S.; Li, L. Grain size dependent tensile behavior of Mg-3\% Al alloy at elevated temperatures. Mater. Sci. Eng. A 2009, 515, 14-18. [CrossRef] 
4. Zhang, X.; Lihua, L.; Naiheng, M.; Haowei, W. Mechanical properties and damping capacity of magnesium matrix composites. Compos. Part A Appl. Sci. Manuf. 2006, 37, 2011-2016. [CrossRef]

5. Manakari, V.; Parande, G.; Gupta, M. Selective laser melting of magnesium and magnesium alloy powders: A review. Metals 2017, 7, 2. [CrossRef]

6. Wong, W.L.E.; Gupta, M. High performance lightweight magnesium nano composites for engineering and biomedical applications. Nano World J. 2016, 2, 78-83.

7. Ferguson, J.B.; Jaberi, F.S.; Kim, C.S.; Rohatgi, P.K.; Cho, K. On the strength and strain to failure in particle-reinforced magnesium metal-matrix nanocomposites (Mg MMNCs). Mater. Sci. Eng. A 2012, 558, 193-204. [CrossRef]

8. Kraus, T.; Fischerauer, S.F.; Hanzi, A.C.; Uggowitzer, P.J.; Loffler, J.F.; Weinberg, A.M. Magnesium alloys for temporary implants in osteosynthesis: In vivo studies of their degradation and interaction with bone. Acta Biomater. 2012, 8, 1230-1238. [CrossRef]

9. Kirkland, N.T.; Birbilis, N. Magnesium Biomaterials: Design, Testing, and Best Practice; Springer International Publishing: Berlin/Heidelberg, Germany, 2014.

10. Yang, Z.; Li, J.P.; Zhang, J.X.; Lorimer, G.W.; Robson, J.A.M.S.E.L. Review on research and development of magnesium alloys. Acta Met. Sin. 2009, 21, 313-328. [CrossRef]

11. Dieringa, H. Properties of magnesium alloys reinforced with nanoparticles and carbon nanotubes: A review. J. Mater. Sci. 2011, 46, 289-306. [CrossRef]

12. Dieringa, H. Processing of magnesium-based metal matrix nanocomposites by ultrasound-assisted particle dispersion: A review. Metals 2018, 8, 431. [CrossRef]

13. Mendis, C.L.; Hono, K. 4-Understanding precipitation processes in magnesium alloys. Fundam. Magnes. Alloy Metall. 2013, 125-151. [CrossRef]

14. Seetharaman, S.; Blawert, C.; Ng, B.M.; Wong, W.L.E.; Goh, C.S.; Hort, N.; Gupta, M. Effect of erbium modification on the microstructure, mechanical and corrosion characteristics of binary Mg-Al alloys. J. Alloys Compd. 2015, 648, 759-770. [CrossRef]

15. Avedesian, M.M.; Baker, H. (Eds.) ASM Specialty Handbook: Magnesium and Magnesium Alloys; ASM International: Almere, The Netherlands, 1999.

16. Chen, J.H.; Shen, Y.C.; Chao, C.G.; Liu, T.F. Wear Behavior and Microstructure of Mg-Sn Alloy Processed by Equal Channel Angular Extrusion. Materials 2017, 10, 1315. [CrossRef] [PubMed]

17. Liu, H.; Chen, Y.; Tang, T.; Wei, S.; Niu, G. The microstructure, tensile properties, and creep behavior of as-cast Mg-(1-10)\% Sn alloys. J. Alloys Compd. 2007, 440, 122-126. [CrossRef]

18. Huang, Y.; Dieringa, H.; Kainer, K.U.; Hort, N. Effects of Sn segregation and precipitates on creep response of Mg-Sn alloys. Fatigue Fract. Eng. Mater. Struct. 2013, 36, 308-315. [CrossRef]

19. Kang, D.H.; Park, S.S.; Kim, N.J. Development of creep resistant die cast Mg-Sn-Al-Si alloy. Mater. Sci. Eng. A 2005, 413, 555-560. [CrossRef]

20. Bowles, A.L.; Dieringa, H.; Blawert, C.; Hort, N.; Kainer, K.U. Investigations in the Magnesium-Tin system. In Materials Science Forum; Trans Tech Publications Ltd.: Zurich, Switzerland, 2005; Volume 488, pp. 135-138.

21. Huang, Y.; Dieringa, H.; Kainer, K.U.; Hort, N. Understanding effects of microstructural inhomogeneity on creep response-New approaches to improve the creep resistance in magnesium alloys. J. Magnes. Alloys 2014, 2, 124-132. [CrossRef]

22. Parande, G.; Manakari, V.; Meenashisundaram, G.K.; Gupta, M. Enhancing the tensile and ignition response of monolithic magnesium by reinforcing with silica nanoparticulates. J. Mater. Res. 2017, 32, 2169-2178. [CrossRef]

23. Kujur, M.S.; Mallick, A.; Manakari, V.; Parande, G.; Tun, K.S.; Gupta, M. Significantly enhancing the ignition/compression/damping response of monolithic magnesium by addition of $\mathrm{Sm}_{2} \mathrm{O}_{3}$ nanoparticles. Metals 2017, 7, 357. [CrossRef]

24. Tekumalla, S.; Nandigam, Y.; Bibhanshu, N.; Rajashekara, S.; Yang, C.; Satyam, S.; Gupta, M. A strong and deformable in-situ magnesium nanocomposite igniting above 1000 C. Sci. Rep. 2018, 8, 7308. [CrossRef]

25. Ferkel, H.; Mordike, B.L. Magnesium strengthened by SiC nanoparticles. Mater. Sci. Eng. A 2001, 298, 193-199. [CrossRef]

26. Labib, F.; Mahmudi, R.; Ghasemi, H.M. Impression creep behavior of extruded Mg-SiCp composites. Mater. Sci. Eng. A 2015, 640, 91-97. [CrossRef]

27. Kumar, H.; Chaudhari, G.P. Creep behavior of AS41 alloy matrix nano-composites. Mater. Sci. Eng. A 2014, 607, 435-444. [CrossRef]

28. Malaki, M.; Xu, W.; Kasar, A.K.; Menezes, P.L.; Dieringa, H.; Varma, R.S.; Gupta, M. Advanced metal matrix nanocomposites. Metals 2019, 9, 330. [CrossRef]

29. Papageorgiou, D.G.; Kinloch, I.A.; Young, R.J. Mechanical properties of graphene and graphene-based nanocomposites. Prog. Mater. Sci. 2017, 90, 75-127. [CrossRef]

30. Kumar, P.; Mallick, A.; Kujur, M.S.; Tun, K.S.; Gupta, M. Effects of graphene nanoplatelets on the tribological, mechanical, and thermal properties of Mg-3Al alloy nanocomposites. Int. J. Mat. Res. 2019, 110, 534-542. [CrossRef]

31. Hu, Z.; Tong, G.; Lin, D.; Chen, C.; Guo, H.; Xu, J.; Zhou, L. Graphene-reinforced metal matrix nanocomposites-a review. Mater. Sci. Technol. 2016, 32, 930-953. [CrossRef]

32. Xiang, S.; Wang, X.; Gupta, M.; Wu, K.; Hu, X.; Zheng, M. Graphene nanoplatelets induced heterogeneous bimodal structural magnesium matrix composites with enhanced mechanical properties. Sci. Rep. 2016, 6, 38824. [CrossRef]

33. Rashad, M.; Pan, F.; Hu, H.; Asif, M.; Hussain, S.; She, J. Enhanced tensile properties of magnesium composites reinforced with graphene nanoplatelets. Mater. Sci. Eng. A 2015, 630, 36-44. [CrossRef] 
34. Kumar, P.; Mallick, A.; Kujur, M.S.; Tun, K.S.; Shabadi, R.; Gupta, M. Strength of Mg-3\% Al alloy in presence of graphene nano-platelets as reinforcement. Mater. Sci. Technol. 2018, 34, 1086-1095. [CrossRef]

35. Kumar, P.; Mallick, A.; Kujur, M.S.; Tun, K.S.; Gupta, M. Synthesis and analysis of Mg-3\% Al alloy nanocomposites reinforced by RGO. Mater. Manuf. Process. 2020, 35, 1650-1660. [CrossRef]

36. Rashad, M.; Pan, F.; Asif, M.; Tang, A. Powder metallurgy of Mg-1\% Al-1\% Sn alloy reinforced with low content of graphene nanoplatelets (GNPs). J. Ind. Eng. Chem. 2014, 20, 4250-4255. [CrossRef]

37. Munir, K.; Wen, C.; Li, Y. Graphene nanoplatelets-reinforced magnesium metal matrix nanocomposites with superior mechanical and corrosion performance for biomedical applications. J. Magnes. Alloys 2020, 8, 269-290. [CrossRef]

38. Ratcliffe, R.T. The measurement of small density changes in solids. Br. J. Appl. Phys. 1965, 16, 1193. [CrossRef]

39. Thenambika, V.; Jayalakshmi, S.; Singh, A.; Nidhi, J.K. Impression creep behaviour of extruded Mg-Sn alloy. Int. J. Veh. Struct. Syst. 2016, 8, 174-178. [CrossRef]

40. Pekguleryuz, M.O.; Kainer, K.U.; Kaya, A.A. Fundamentals of Magnesium Alloy Metallurgy; Woodhead Publishing Ltd.: Cambridge, UK, 2013.

41. Peng, Y.; Deng, K. Study on the mechanical properties of the novel Sn-Bi/Graphene nanocomposite by finite element simulation. J. Alloys Compd. 2015, 625, 44-51. [CrossRef]

42. Gupta, M.; Sharon, N.M.L. Magnesium, Magnesium Alloys, and Magnesium Composites; John Wiley \& Sons: Hoboken, NJ, USA, 2011.

43. Ahmad, I.; Islam, M.; Subhani, T.; Zhu, Y. Toughness enhancement in graphene nanoplatelet/SiC reinforced Al2O3 ceramic hybrid nanocomposites. Nanotechnology 2016, 27, 425704. [CrossRef]

44. Johanes, M.; Tekumalla, S.; Gupta, M. $\mathrm{Fe}_{3} \mathrm{O}_{4}$ nanoparticle-reinforced magnesium nanocomposites processed via disintegrated melt deposition and turning-induced deformation techniques. Metals 2019, 9, 1225. [CrossRef]

45. Ceschini, L.; Dahle, A.; Gupta, M.; Jarfors, A.E.W.; Jayalakshmi, S.; Morri, A.; Rotundo, F.; Toschi, S.; Singh, R.A. Aluminum and Magnesium Metal Matrix Nanocomposites; Springer: Berlin/Heidelberg, Germany, 2017.

46. Ogurtani, T.O.; Dogukan, S.; Buke, G.C. Wrinkling of graphene because of the thermal expansion mismatch between graphene and copper. Surf. Interface Anal. 2018, 50, 547-551. [CrossRef]

47. Saba, F.; Zhang, F.; Liu, S.; Lie, T. Reinforcement size dependence of mechanical properties and strengthening mechanisms in diamond reinforced titanium metal matrix composites. Compos. Part B Eng. 2019, 167, 7-19. [CrossRef]

48. Tun, K.S. Development and Characterization of New Magnesium Based Nanocomposites. Ph.D. Thesis, National University of Singapore, Singapore, 2009.

49. Sankaranarayanan, S.; Nayak, U.P.; Sabat, R.K.; Suwas, S.; Almajid, A.; Gupta, M. Nano-ZnO particle addition to monolithic magnesium for enhanced tensile and compressive response. J. Alloys Compd. 2014, 615, 211-219. [CrossRef]

50. Kujur, M.S.; Manakari, V.; Parande, G.; Tun, K.S.; Mallick, A.; Gupta, M. Enhancement of thermal, mechanical, ignition and damping response of magnesium using nano-ceria particles. Ceram. Int. 2018, 44, 15035-15043. [CrossRef] 